Rev. Est. de Políticas Públicas, 5(1): diciembre 2018 - junio 2019, 50-70

http://dx.doi.org/10.5354/0719-6296.2019.52398

ISSN edición web: 0719-6296

CCopyright 2019: Universidad de Chile, Santiago (Chile)

\title{
Nuevas prácticas y significados en políticas públicas saludables en los ámbitos locales de Venezuela
}

\author{
Jorge Mandl y Hernán Málaga \\ Ministerio del Poder Popular para la Salud, Venezuela y Universidad Ricardo Palma, Perú
}

\section{Resumen}

Esta investigación realizada en cinco municipios rurales de Venezuela, estuvo orientada a evidenciar como las políticas públicas saludables son consecuencia de un conjunto de interacciones entre el Estado y la sociedad civil que impulsan la construcción de nuevas articulaciones politicas y sociales, determinando una práctica local para la salud y el bienestar. Se seleccionó el paradigma cualitativo, asumiendo la fenomenología así como elementos hermenéuticos. El estudio demostró la construcción colectiva de propuestas hacia una nueva cultura política dirigida a universalizar los derechos básicos, la justicia y equidad. Los significados revelaron que las políticas públicas saludables constituyen una secuencia de respuestas integradas y sostenidas, resultado de procesos multisectoriales y transdisciplinarios del Estado con mediación social, cuyas dinámicas participativas garantizan llevar objetivos comunes a la praxis y asumir compromisos con el fin de actuar sobre aquellos determinantes sociales de la salud que determinan las transformaciones sobre la calidad de vida

Palabras clave: Politicas públicas saludables, capital social, Venezuela.

New practices and meanings in healthy public policies in the local areas of Venezuela

\begin{abstract}
This study conducted in five rural municipalities of Venezuela, was oriented to show as healthy public policies are the result of a set of interactions between the State and civil society that promoting the construction of new political and social that determine a local practice for health and well-being. It selected the qualitative paradigm, taking phenomenology as well as hermeneutic elements. The study showed the collective construction of proposals towards a new political culture to universalize basic rights, justice and equity. The meanings revealed that healthy public policies are a sequence integrated and sustained responses in all State policies, result of multi-sectoral and cross-disciplinary processes with social mediation, whose dynamic participatory guarantee an real and equitable opportunity of the society to carry them objectives common to the praxis and assume commitments to act on those determinants social of it health that establish transformations on the quality of life
\end{abstract}

Keywords: Healthy public policies, social capital, Venezuela

*Dirección de correspondencia [Correspondence address]:

Jorge Mandl, Ministerio del Poder Popular para la Salud, Venezuela

E-mail: jorge_mandl@yahoo.com

Fecha recepción: 19 de febrero de 2018

Fecha aceptación: 23 de abril de 2018 


\section{Introduccion}

Las políticas públicas saludables se caracterizan por un interés positivo por la salud y la equidad en todas las dimensiones de la política y por un compromiso sobre su impacto en la salud (Segunda Conferencia Internacional sobre Promoción de la Salud: Políticas públicas saludables, 2008). Llevan implícita la propuesta de un gobierno mancomunado; procesos sistemáticos que tomen en consideración las interacciones coordinadas entre los diferentes sectores; mediación entre los diversos intereses; procesos de participación, rendición de cuentas y transparencia; compromiso de partes interesadas de la sociedad civil e iniciativas prácticas que establezcan alianzas y confianza (Declaración de Adelaida sobre la Salud en Todas las Políticas, 2010). Estas transformaciones entrañan un largo camino de aprendizaje para construir una nueva cultura política vinculada con el capital social como eje articulador entre el Estado y las comunidades (Canto Chac, 2008), donde se privilegien las potencialidades locales para el desarrollo productivo y se le otorgue a los ciudadanos la posibilidad de participar en la búsqueda de soluciones a sus necesidades básicas insatisfechas relacionadas con los determinantes sociales de la salud (Commission on Social Determinants of Health, 2008).

Investigaciones llevadas a cabo en 1992, con el fin de verificar conexiones entre necesidades básicas insatisfechas en los ámbitos municipales (Universidad Central de Venezuela y Ministerio de Salud y Asistencia Social, 1993), demostraron la asociación entre condiciones de vida y salud, expresada por las grandes diferencias en oportunidades de vida de las poblaciones, correspondiendo su postergación con exclusión social o falta de justicia social (Málaga, 1998) que no había sido intervenida con políticas públicas acordes a esta realidad por parte del Estado, lo que se tradujo en mantenimiento o profundización de las brechas existentes, fundamentalmente en los ámbitos locales, debido a liderazgos políticos y comunitarios con poca posibilidad de convocatoria y escasa capacidad de respuesta sobre los determinantes sociales que afectan la salud (Toba Darriba, 1996; Lacruz, 2006) (Tabla 1). En tal sentido, comenzaron a desarrollarse un conjunto de iniciativas que apuntan a la construcción de ciudadanía, fundamentada en la universalidad de los derechos sociales y el reconocimiento expreso de los sujetos de estos derechos; la búsqueda de la justicia y equidad como objetivo supremo del ordenamiento político, económico y social; el rescate de lo público, como ámbito para el ejercicio de una verdadera democracia; y la articula- ción colectiva local como espacio de convergencia de la identidad y subjetividades de los ciudadanos para proteger su libertad de actuación y decisión (D'Elia y De Negri, 2006).

En este contexto, se presentaron dos criterios o fundamentos doctrinales e ideológicos: por un lado, desde 1994 hasta 1999, la estrategia de Municipios Hacia la Salud - con 64 iniciativas desarrolladas en el $75 \%$ de las entidades federales del país-, que adoptaron una perspectiva de democracia deliberativa para el desarrollo de oportunidades de vida (Málaga, 1996) referido al concepto de justicia distributiva de Rawls y el enfoque de desarrollo de las libertades-capacidades para la generación de una vida digna propuesto por Amartya Sen; por el otro, la estrategia de las Misiones Bolivarianas -desplegadas en el $100 \%$ de los municipios-, que en el plano funcional surgieron a partir del año 2003 inspiradas en la democracia participativa y protagónica del modelo socialismo del siglo XXI que se asienta en los principios de igualdad, inclusión social y ciudadanía plena planteados en el pensamiento de Rousseau, David Held y Stuart Mill. Esta descripción señala la necesidad de analizar críticamente diversas cualidades sobre la base de una valoración ético-política y el conocimiento del contexto histórico en el que se aplicaron sus estrategias.

Ambos procesos estuvieron apoyados en proyectos comunitarios cuyos principales objetivos se centraron en la disminución y mitigación de las consecuencias de las desigualdades sociales a través de la distribución equitativa de recursos, servicios, oportunidades y capacidades, los cuales fueron dirigidos a construir y conservar el capital social. Por el otro, se organizaron subestructuras relacionadas con el concepto de bienestar social, sustentados en programas para obtener dicho fin, haciendo referencia a un conjunto de mandatos que contribuyeron al mejoramiento de una situación ya existente y anticipada.

Rev. Est. de Políticas Públicas, 5(1): diciembre 2018 - junio 2019 


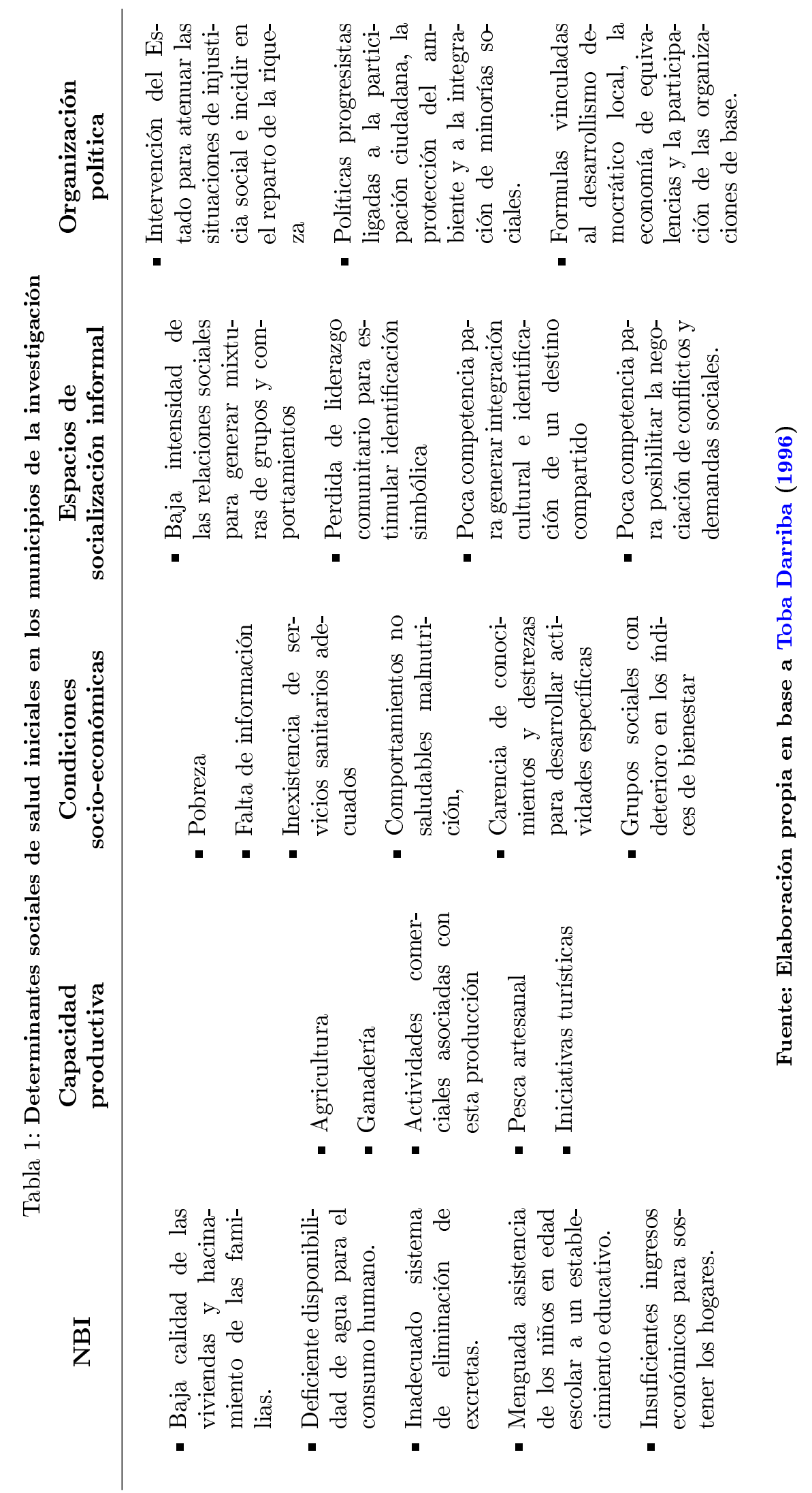


Mediante la interacción de sectores gubernamentales y no gubernamentales como agricultura, comercio, educación, deporte, industria entre otros, se implementaron políticas interesadas en posibilitar la redistribución del poder e impulsar la construcción de nuevas arquitecturas de articulaciones sociales, con el fin de establecer una práctica local de gobernanza para la salud y el bienestar. Bajo esta premisa, un $36 \%$ de los proyectos se relacionaron con saneamiento básico, $24 \%$ abarcaron acciones de prevención de enfermedades basados en estilo de vida, un $12 \%$ abarcaron el desarrollo de servicios públicos, el $11 \%$ correspondieron al área de educación, $10 \%$ incluyeron proyectos para fomentar el empleo; y un $7 \%$ afectaron servicios de atención a grupos de riesgo (Mandl, 2018).

Entre los factores facilitadores que marcaron estos procesos, se destacaron: la tradicional participación ciudadana inclusiva en estos municipios, la aparición de nuevas formas de organización y estructuración para la construcción de espacios vitales en los ámbitos locales y la enorme movilización de recursos del Estado y de la sociedad venezolana procurando hacer realidad los derechos para toda la población, particularmente para aquella que acumulaba la mayor deuda de inequidad. Sin embargo, se presentaron factores limitantes para en desarrollo de políticas favorables para la salud, entre las cuales destacamos: la participación y representación sesgadas o no comprometidas con el bien común en algunos actores, el déficit informacional característico de la fragmentación y segmentación institucional y la limitada disposición hacia la rendición de cuentas.

El presente artículo presenta los resultados de una investigación cualitativa que trata de interpretar y comprender las nuevas prácticas y significados que emergen de las relaciones intersubjetivas y capacidad de las organizaciones comunitarias; la cohesión y control de la interacción colectiva, soporte emocional, confianza, sentimiento de pertenencia, entre otras habilidades y competencias. Así mismo, la estrecha vinculación con el concepto de aprendizaje social del Estado que hace hincapié en el papel de los saberes y percepciones populares en la elaboración de políticas públicas saludables en los ámbitos locales de Venezuela y su impacto sobre la expectativa de vida y la mortalidad materno-infantil durante el periodo 1994-2013.

\section{Materiales y métodos}

En esta investigación, el objetivo general planteado fue interpretar las nuevas prácticas y significados de las políticas públicas saludables en los ámbitos locales de Venezuela. Los objetivos específicos buscados abarcaron: describir el contexto sociopolítico de las políticas públicas saludables en el país; comprender los mecanismos e instancias de participación en municipios seleccionados; señalar las nuevas prácticas y significados de que emergen de las diversas formas organizativas participativas comunitarias; reconocer su impacto sobre los indicadores de salud y elaborar aportes teóricos en el contexto de la democracia venezolana.

En cuanto a la delimitación temporal para el desarrollo de la investigación, el periodo comprendió entre 2010 y 2015; asimismo, con respecto al proceso en estudio, se analizo el lapso abarcado desde 1994 hasta 2013. Con relación a la delimitación contextual, esta se fundamento en las perspectivas de las políticas públicas saludables que se desarrollaron en Venezuela, desde su inicio en 1994 hasta la finalización del proyecto Municipios Hacia la Salud en 1999; y en la propuesta de gobierno de la Republica Bolivariana de Venezuela desarrollada a partir del año 2000.

La pesquisa se centró en cinco municipios rurales - Zamora, estado Falcón; Tinaquillo, estado Cojedes; Sucre, estado Portuguesa; Moran y Andrés Eloy Blanco, estado Lara - con altos índices de necesidades básicas insatisfechas, ubicados en la franja centro-occidental de Venezuela y seleccionados por su relevancia de lo político en la promoción de la salud en coherencia con los siguientes criterios: grado de conciencia y compromiso, desempeño en el proceso político, capacidad para impulsar e implementar acciones, infraestructura local para dar sostenibilidad y resultados en relación con los cambios esperados que facilitaron: alianzas estratégicas, políticas públicas, participación ciudadana, ambientes promotores de salud y, sostenibilidad para el desarrollo local (De Salazar y Díaz Grajales, 2004); así como su tradición cultural en cuanto a participación ciudadana en salud.

Para ello se seleccionó el paradigma cualitativo, con el fin de analizar la dinámica de los procesos de cambio en el marco del contexto socio-político a través de los significados de las narrativas de los actores (Vasilachis de Gialdino, 2009), así como describir y comprender las políticas públicas saludables desde la subjetividad como espacio de construcción de cali- 
dad de vida y salud, y la inter-subjetividad y el consenso como vehículos para acceder al conocimiento válido de esta realidad (Gurdián-Fernández, 2007). Con este propósito, se recurrió a la fenomenología de Maurice Merleau-Ponty como marco referencial teórico-filosófico. Para la comprensión e interpretación de los discursos, se adoptaron las reflexiones de la fenomenología-hermenéutica de Paul Ricoeur.

Como técnica de investigación se conformaron grupos focales, con los cuales, en un mismo proceso de deliberación pública (Martínez Miguélez, 2004), se expresaron argumentos y acciones desde los propios proyectos de vida buena de los actores, el reconocimiento del otro y la capacidad de respetar la interacción histórico-contextual vivida, así como la distribución de bienes y servicios por parte del Estado.

Consideramos delimitar el estudio en dos cursos de tiempo: un primer momento comprendido entre 1994 y 1999 y otro momento entre 2000 y 2013. En cada periodo interactuaron: comunidad organizada, alcaldes, concejales, servidores públicos adscritos a organismos gubernamentales y sociedad civil amparada con las propuestas elaboradas para los periodos inquiridos. En este sentido, se estructuraron ocho unidades de observación con la participación de cinco actores relevantes en cada una de ellas, para un total de doscientos actores socio-políticos que aportaron sus vivencias en los grupos focales.

Para seleccionar sus integrantes, se empleó un muestreo intencionado mediante informantes clave voluntarios, que posteriormente recomendaron posibles participantes. Conforme avanzo la práctica, se utilizó una estrategia de muestreo deliberado (Martínez-Salgado, 2012) con participantes escogidos, basándonos en función de su experiencia como actores del proceso su disponibilidad para participar y su capacidad para satisfacer tres requisitos básicos: ser coherente, pertinente y eficaz para explorar el tema en estudio, tener la capacidad de proveer todas las respuestas que se requieren para comprobar la tesis y poseer la aptitud de revelar datos y argumentos inesperados que eventualmente sirvan para la confrontación de ideas. En la implementación, se diseño una guía con quince preguntas generadoras, abiertas y sencillas de entender, previamente sometidas a una prueba piloto; las sesiones de trabajo se desarrollaron en dos horas cada una de ellas y, con la finalidad de que las observaciones aparecieran las más exhaustivas posibles, fueron filmados y grabados, previo consentimiento del colectivo.
El marco analítico utilizó un recorrido constante y circular de los fenómenos (Salamanca y MartínCrespo, 2007) que giraron alrededor de factores correspondientes a los intereses materiales de los actores, los componentes estructurales que influyeron en los procesos de formación de las políticas públicas saludables y en la centralidad de los elementos simbólicos (Mayz Díaz, 2009).

La comprensión e interpretación pudo asumirse como un proceso transdisciplinario que ameritó combinar y acoplar métodos dirigidos a explicar tanto las interacciones entre actores, instituciones, intereses e ideas, como la naturaleza de los valores y destrezas que emergieron de tales interacciones. A partir de estas observaciones y las propias palabras de las personas, por medio de técnicas de codificación y categorización que implicaron la interpretación de los hechos, la comprensión de la experiencia, el trato holístico de los fenómenos y la construcción de conocimientos (Glasser y Strauss, 1967; Strauss y Corbin, 1998); se propuso describir los elementos, permitiendo explicar la construcción de capital social en las experiencias vitales de los actores que participaron en la formulación y puesta en marcha de las políticas públicas saludables; asimismo, comprender cómo los significados de los discursos resultantes, facilitaron el acoplamiento del deseo de vivir bien, con y para otros, en instituciones justas.

Este procedimiento incluyó la descripción del campo fenomenológico de los actores y la comprensión propia de la naturaleza vivida (Roth Deubel, 2008); el proceso reflexivo que se produjo con base en la identificación de atributos que emergieron de los relatos (Dantas Guedes y Moreira, 2009); la elaboración de categorías presentes en las manifestaciones de los actores sociales y la posible percepción de estos en un determinado momento histórico (Botelho Josgrilberg, 2008) y; el control transversal entre diferentes fuentes de datos que permitieron la integración de resultados, llegando a la interpretación, generando conclusiones y recomendaciones de la investigación (Figura 1).

Los resultados descritos por los actores que interactuaron reflejaron maneras de pensar sobre el mundo y cómo actuar en él, en la medida que englobaron modelos implícitos y algunas veces explícitos de una sociedad y de visiones de como los individuos debieron relacionarse con su conjunto y los unos con los otros, recorriendo todas las etapas del proceso de formulación de políticas públicas saludables a partir de problemas sociales, atravesando toda la plataforma del sistema político e institucional, de tal manera

Rev. Est. de Políticas Públicas, 5(1): diciembre 2018 - junio 2019 
Figura 1: Senda metodológica de la investigación

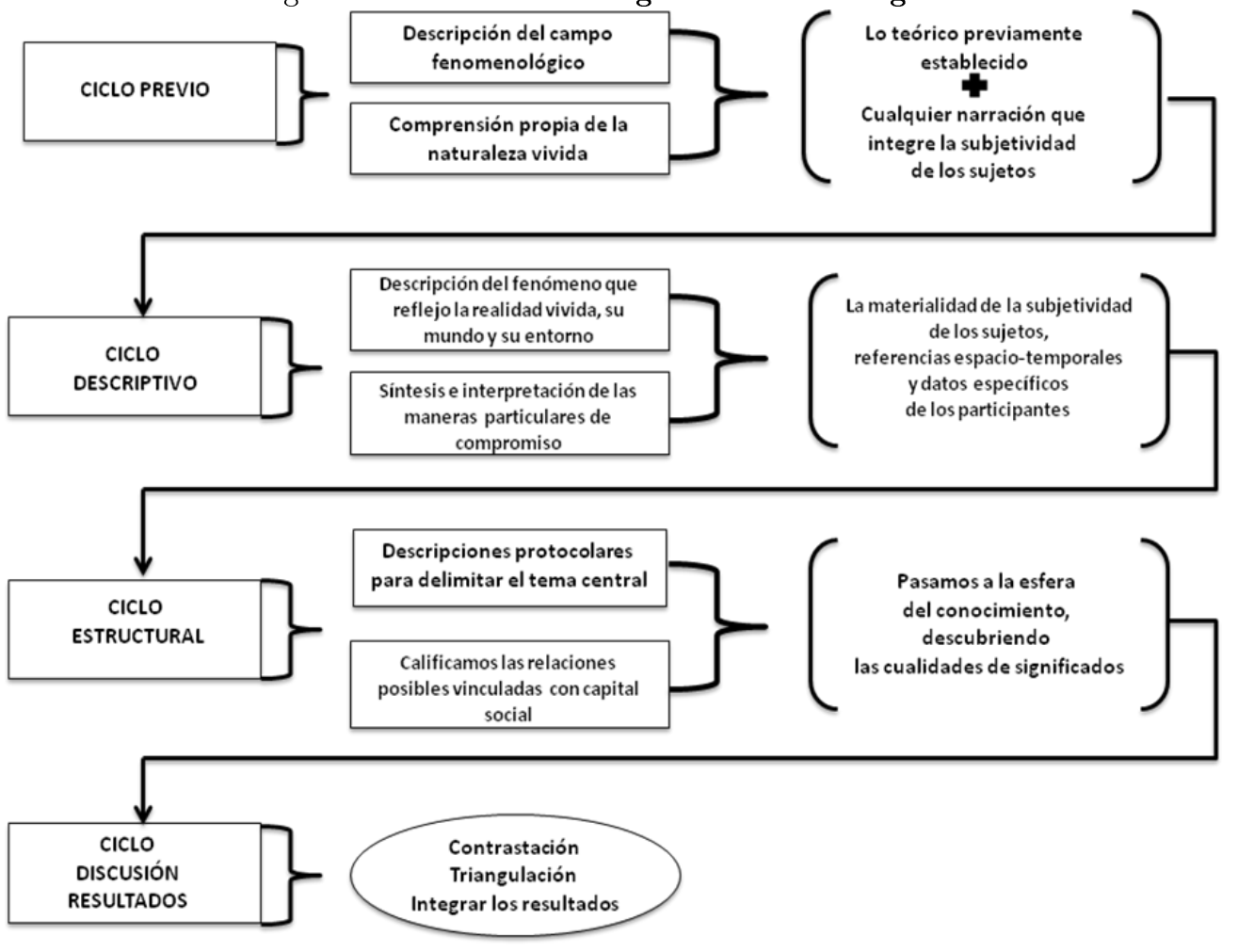

Figura 1. Senda metodológica de la investigación. Elaboración propia

Fuente: Elaboración propia.

que otorgaron consistencia, orientación y confianza a las acciones.

Con relación al análisis documental, se relacionaron y confrontaron los resultados fenomenológicamente descritos con aquellos estudios afines que se anunciaron en el marco teórico referencial, para ver cómo emergían desde perspectivas diferentes sobre propuestas conocidas más amplias y, de esta manera, se expuso con mayor asertividad lo que el estudio verdaderamente significó.

Una vez concluida la contrastación, se procedió a comprobar si las diversas investigaciones reseñadas en el marco referencial de la investigación, llegaron a conclusiones similares, como también, si los resultados obtenidos pudiesen encontrarse en otras fuentes. Con este propósito se utilizó la triangulación de datos en distintos momentos de la investigación. Estos testimonios e informaciones fueron recogidos de distintas localidades para comprobar las coincidencias y se recurrió a distintos grupos de sujetos para verificar los resultados (Ruedas Marrero et al., 2009).

Por último, se integro en un todo coherente y ló- gico los resultados de la investigación, ampliándolos con los aportes de los autores reseñados. Con relación a expectativa de vida, la mortalidad infantil y materna, solo se alcanzó a obtener información completa en tres de los municipios investigados. Según los informantes, esto se debió a: 1) no se encontraron registros descriptivos y datos anteriores a 1999 en los archivos del gobierno local ni en las dependencias de los organismos correspondientes, además muchos de los actores responsables de llevar y/o procesar dichos resultados ya no residen en la localidad o han fallecido; 2) con respecto a los informes de los años posteriores, existe la disposición cultural y política de algunos funcionarios para no suministrar información.

La validación y confiabilidad se enfrentó a tres compromisos: en primer lugar, a nuevas y reemergentes correlaciones con los participantes; en segundo término, a posicionamientos técnicos, personales y políticos hacia el uso de la misma y su potencialidad para promover la acción y; finalmente, a una visión que posibilito y fomento la justicia social con equidad, la diversidad y el discurso deliberativo (Lefevre y A.M, 2014). La investigación no solo se

Rev. Est. de Políticas Públicas, 5(1): diciembre 2018 - junio 2019 
oriento a generar conocimientos, sino también para contribuir a la solución de problemas relevantes. Estos senderos dependieron de la creatividad, sensibilidad, flexibilidad y habilidad para responder a lo que sucedió durante el estudio; coherencia metodológica; la selección de participantes que mejor representaron o tuvieron conocimiento del fenómeno investigado; la interacción entre la recolección y el análisis de la información y; la saturación de las narraciones (Sandín Esteban, 2000).

\section{Resultados}

La información obtenida en los grupos focales se sistematizó en cuatro construcciones que caracterizan al capital social (Lochner et al., 1999; Sapag y Kawachi, 2007): sentido psicológico de comunidad o sentido de comunidad, eficacia colectiva, capacidad comunitaria y competencia comunitaria; que a su vez se dividieron en catorce subcategorías. La conexión que se estableció entre cada categoría de análisis, los registros oficiales y las publicaciones consultadas hicieron que se cumpliese con los objetivos propuestos en la investigación.

Para una mejor comprensión del texto, se señala la codificación asignada a las categorías, subcategorías y unidades de análisis de la investigación; que reflejo puntualmente la organización del contenido del documento; favoreciendo, por una parte, la comprensión en profundidad de las situaciones estudiadas y, por otra, el diseño y aplicación de estrategias contextualizadas orientadas al logro de los objetivos propuestos (Tabla 2).

\subsection{Sentido psicológico de comunidad o sentido de comunidad}

En las experiencias analizadas, la solidaridad y la responsabilidad social constituyeron los principios cardinales que facilitaron la organización de las comunidades; a partir de estos preceptos, cada individuo experimento subjetivamente su participación en una colectividad mayor al incorporarse a redes que privilegian la promoción de la salud. Estos tejidos sociales fueron inicialmente dirigidos hacia la satisfacción de necesidades sentidas y reales comunes.

La principal cualidad fue la solidaridad social. La solidaridad y la responsabilidad social que constituyen los valores a trabajar por el bien de la comunidad.

(A.1.GF1)
Mediante la participación, la solidaridad, la honestidad, la transparencia de las comunidades y los equipos gubernamentales pudimos generar confianza y convivencia y por ende calidad de vida entre los ciudadanos, despertando el sentido de pertenencia.

(A.1. GF5)

Se logró generar una gran solidaridad entre el equipo de funcionarios públicos y las Comunidades para integrar un equipo multidisciplinario y cohesionado, con capacidad de servicio bien desarrollado y políticas públicas bien definidas y metas claras.

(A.2.GF3)

Para desarrollar el sentido de pertenencia se crearon los Comités de Salud lo que permitió que la Comunidad descubriera sus propias necesidades.

(A.1. GF4)

La creación de los Consejos Comunales en la comunidad fue predominante para determinar las necesidades y ser resueltos en los mismos. (A.3.GF8)

La promoción de salud se ejerció como estrategia de integración para la satisfacción de necesidades, la idea básica era satisfacer necesidades comunes mediante participación humanitaria, solidaria, comunicativa y compañera.

(A.3.GF2)

Los elementos que moldearon esta valoración fueron la percepción de similitud con otros, el reconocimiento de la interdependencia con los demás, el sentimiento de que uno es parte de una estructura más amplia, estable y fiable, y la voluntad de mantener esa interdependencia dando o haciendo por otros lo que uno espera de ellos.

Somos todos de por estos lados, por lo tanto conozco de las fortalezas y debilidades de esta nuestra tierra para la ejecución de proyectos comunitarios, el tuyo, el mío, el de los otros, las ganas de hacerlo porque es nuestro, todos sumados por el beneficio colectivo.

(A.1.GF1)

Contar con el apoyo del colectivo, enfrentar unidos la problemática y agruparse en función

Rev. Est. de Políticas Públicas, 5(1): diciembre 2018 - junio 2019 
Tabla 2: Categorias de análisis

\section{Categorías}

\begin{tabular}{ll}
\hline \multirow{2}{*}{$\begin{array}{l}\text { A. Sentido de } \\
\text { comunidad }\end{array}$} & $\begin{array}{l}\text { 2. Pertenencia de grupo } \\
\text { a través de normas comunitarias }\end{array}$ \\
& $\begin{array}{l}\text { 3. Integración para satisfacción } \\
\text { de las necesidades } \\
\text { 4. Conexión emocional compar- } \\
\text { tida }\end{array}$ \\
& 1. Cohesión social \\
B. Eficacia & 2. Control social informal \\
colectiva & 1. Participación deliberativa y \\
& reflexión crítica \\
C. Capacidad & 2. Liderazgo \\
comunitaria & 3. Redes de apoyo resolutivas \\
& 4. Habilidades y recursos \\
& 5. Comprensión de la historia, \\
& $\begin{array}{l}\text { articulación de valores y acceso } \\
\text { al poder }\end{array}$ \\
& 1. Compromiso con la comuni- \\
dad Competencia & 2. Apoyo social de la Comunidad \\
comunitaria & 3. Mecanismos de articulación
\end{tabular}

Unidades de análisis

- GF1 Comunidad organizada que participó en el proyecto Municipios Hacia la Salud

- GF2 Alcaldes y Concejales con mandato por elección popular que se encontraban ejerciendo entre los años 1994-1999

- GF3 Servidores públicos adscritos a organismos gubernamentales durante los 1994-1999

- GF4 Sociedad civil amparada con las propuestas del proyecto Municipios Hacia la Salud

- GF5 Voceros de los Consejos Comunales que desarrollaron y desarrollan proyectos comunitarios entre los años 2000 y la actualidad

- GF6 Alcaldes y Concejales con mandato por elección popular que se encontraban y encuentran ejerciendo entre los años 2000 hasta la actualidad

- GF7 Servidores públicos adscritos a organismos gubernamentales durante los años 2000 hasta la actualidad

- GF8 Sociedad civil amparada con las propuestas de los Consejos Comunales

\section{Fuente: Elaboración propia.}

de las actividades comunes para así lograr el objetivo planteado de acuerdo a las necesidades de la comunidad.

(A.2.GF5)

El bienestar común que todos convivimos en el mismo medio y el deber de ciudadanos y que perduren las cosas, bien sea la armonía como la integridad del hogar y personas puesto la convivencia es humana.

(A.2. GF4)

Desarrollamos un trabajo participativo Comunidad-Alcaldía, a través de la organización de las comunidades, de manera que las Comunidades descubrieran cuáles eran sus necesidades para abordarlas en conjunto desde la propia Comunidad.

$$
\text { (A.3.GF2) }
$$

Producto de este reconocimiento mutuo como partícipes de la acción solidaria y como visión de futuro de los hechos y lugares que consideran propios como base de su percepción del mundo y de su lugar en el mismo, surgió una identidad grupal como base conceptual trascendental para generar una cultura política propia, impulsando roles sociales, costumbres y normas éticas como la co-responsabilidad, la libertad con objetivos sociales compartidos, el compromiso o la capacidad de promesa, la capacidad crítica a partir de la confianza y la voluntad constante de practicar el amor y la justicia, con el objeto de transformar su entorno.

El compartir cotidianamente con las comunidades donde se estaba implementando las políticas públicas saludables, consiguió que organizáramos equipos de trabajo corresponsables de los objetivos, metas y actividades que se iban llevando a cabo.

$$
\text { (A.4.GF3) }
$$

El compromiso primero es individual para que pueda extenderse al compromiso colectivo al 
comenzar el intercambio de ideas y aclarar lo que busca con cada una de las áreas, las propuestas, indagar qué punto de compenetración existe entre el grupo, la Alcaldía y el medio ambiente.

(A.4.GF6)

Se encontró una gran responsabilidad con el equipo y un excelente compromiso por parte de las comunidades. Se desarrolló un trabajo para generar un estado de conciencia social en el municipio y se organizó un equipo multidisciplinario.

(A.4.GF3)

Lo fundamental para nosotros es la lealtad con nuestra institución y sus normas, la confianza con las comunidades y que cada cual identifique sus funciones para lograr objetivos compartidos.

(A.4.GF7)

La motivación principal fue cultivar el amor y la justicia con nuestra comunidad para que tuviera la oportunidad para desarrollarse como mejores ciudadanos.

(A.4.GF5)

El interés por el tema o problema para resolver, nos hacia sentir que teníamos un compromiso similar con nuestra comunidad y nos convencíamos que sus decisiones serian determinantes para solucionar o manejar los problemas. Teníamos la sensación de avance permanente en el logro de objetivos y aprendizaje constante por parte de cada uno de los miembros del equipo.

(A.4.GF2)

De este modo, los ciudadanos se relacionaron en un despliegue de sentido de conectividad social dentro de un sistema político con cultura heterogénea, en cuyo marco fueron construyendo la agenda participativa para una vida buena a través del diálogo, del acuerdo con todas las fuerzas sociales, políticas y económicas que operan en el ámbito local. Una especie de contrato en el que tanto el Estado como la sociedad se concienciaron de sus derechos, pero también de sus obligaciones.

El elemento fundamental fue la innovación y de esta manera la comunidad se motivo a la participación de las soluciones de las necesidades que puedan aquejar a la misma y a su vez lograr establecer la prioridad. Aquí lo más importante fue que las mismas descubrieron que podían trabajar con el Gobierno Municipal y aportar grandes soluciones para desarrollar un plan conjunto.

(A.3.GF1)

Llevamos a cabo visitas a las comunidades, permanencia en las mismas así como entender que son ellos los que conocen de primera mano lo que necesitan. La participación del Gobierno Municipal le vio como un apoyo técnico y no como quien imponía las soluciones. (A.3.GF5)

Existen líderes en cada comunidad pero bien es cierto que deben estar entrelazados en los diferentes programadores del Estado ya que es el Estado quien deberá garantizar toda herramienta para el desempeño de cada proyecto y que este llegue a la comunidad que más necesita para alcanzar excelente calidad de vida.

(A.3.GF8)

Esta agenda participativa fue posible gracias al funcionamiento al unísono de todos los elementos mencionados bajo la batuta de la mediación emocional, perseverancia y el conocimiento desde la percepción tal como es vivida, que permitió a los actores actuantes atribuirle sentido a sus conductas y encaminarlas en función de los motivos de los demás, en su dimensión de integración. Compartir conocimientos sobre la realidad propia y solidarizarse con las necesidades del otro transformó a los actores sociales en una sola familia y el logro o beneficio de uno, garantizó el beneficio colectivo.

Las vivencias interpersonales entre los diferentes actores sociales permitieron reconstruir la realidad social y tomar de conciencia de ella, aprobó el diseño de propuestas integradas donde identificábamos, elaborábamos e implementábamos políticas públicas saludables.

(A.3.GF2)

Se formaron y capacitaron gobiernos comunitarios en cada caserío y barrio que conforman el municipio con intereses comunes. El compartir cotidianamente con las comunidades donde se estaba implementando las polí-

Rev. Est. de Políticas Públicas, 5(1): diciembre 2018 - junio 2019 
ticas públicas saludables consiguió que los actores sociales sintieran al equipo de trabajo como una gran familia lo que permitió tener un conocimiento amplio y profundo de las necesidades reales de las comunidades.

\section{(A.3.GF3)}

Como consecuencia de esto se desarrollaron los grupos de trabajo según problemas abordables; y que ese aprendizaje puede ser trasmitido a futuras generaciones.

(A.3.GF5)

Esto se logró mediante la implementación de diversas herramientas de planificación estratégica, que permitieron conformar equipos de trabajo comunitario para incluir población vulnerable en una comunidad deseosa de que se le tomara en cuenta, con motivación para aportar saberes en un proceso de aprendizaje compartido con beneficio agregado. Ello se alcanzo gracias a la acción de facilitadores externos.

A través de diagnósticos participativos en las comunidades de los cuales surgieron las necesidades y problemas a identificar y priorizar para abordar las soluciones. Para ello se convoco a la comunidad, reuniones de trabajo y se le dictaron talleres por parte de facilitadores, para que la comunidad desarrollara sus propios proyectos.

$$
\text { (A.3.GF6) }
$$

Asesores de diferentes organismos, contribuyeron a desarrollar un discurso favorable para participar en el diseño de proyectos comunitarios mediante un método ágil, dinámico y flexible como lo es el marco lógico que permite actuar, interactuar con la comunidad y otras instituciones.

\section{(A.3. GF2)}

\subsection{Eficacia colectiva}

En estas iniciativas, las personas y sus derechos se formaron solamente en la interacción social y en el contexto de ciertas instituciones sociales y políticas bien cohesionadas. Por lo tanto, la posibilidad de creencias y valores compartidos sobre el bien común, de las experiencias vividas y necesidades compartidas en un diálogo abierto por los actores, se establecieron solo cuando la sociedad proporciono un acceso más equitativo a las decisiones que impactaron sobre las vidas de la gente.
Para la identificación de los problemas, de las necesidades del colectivo más desamparado, se tomo en cuenta las edades, la salud, educación, las necesidades y físicas o estructurales como los servicios públicos, según las capacidades de cada quien.

(B.5.GF4)

Se presentaron aspectos prioritarios, relacionados con los estilos de vida, problemas sociales y económicos y la atención a grupos cuyos derechos habían sido vulnerados como son los niños, jóvenes, mujeres, ancianos; se elaboraron proyectos dirigidos a la protección social, al control de la delincuencia, a la creación de áreas de recreación y deporte, de ambientes libres, a la regularización del consumo de alimentos, medicamentos, a la regularización de la vialidad, al fomento de actividades sanas y recreativas como las culturales, folklóricas, deportivas, etc..

(B.5.GF1)

Buscamos el bien común en el sentido de ver al prójimo, la mejor convivencia, seguimiento de normas, moral como éticas, educación, religión $\mathrm{y}$ principios.

(B.5.GF8)

Para movilizar voluntades en torno a las propuestas, se usaron discursos sobre la posición de los participantes en la sociedad, precedido por una relación de pertenencia, de las costumbres, por las normas socialmente aceptadas y por todo tipo de simbolismos. Para ello, se impulso la transformación del imaginario social mediante una narrativa social inclusiva enraizada en el deseo de mejor calidad de vida con y para el otro en organizaciones justas.

Informar y comunicar como se va a realizar las actividades, cultivar la armonía los pro y los contra de punto y selección los verdaderos protagonistas de cada grupo, no dejando pasar los valores humanos y familiares de cada quien. (B.5.GF1)

Propusimos nuestras decisiones en asambleas comunitarias, planteando la importancia para el colectivo de actuar con principios como la solidaridad, humanidad, compromiso social, convivencia, respeto, amor, tolerancia, equidad social.

(B.5.GF5)

Rev. Est. de Políticas Públicas, 5(1): diciembre 2018 - junio 2019 
En cada comunidad se logro que sus habitantes formaran parte en la solución de sus propios problemas.

(B.5.GF4)

Bajo este diseño, se consolidaron los valores de la comunidad, respetando la conciencia de cada persona, respetando y apoyando a las instituciones políticas y sociales que apoyan a las comunidades hacia valores compartidos, valores que garantizan los derechos básicos y que se constituyen en una oportunidad política de acceder al poder a través de proyectos comunitarios.

Desarrollamos proyectos de intervención social, donde cada individuo según sus habilidades y destrezas, por afinidad y espontáneamente se incluyera en el grupo acorde a sus facultades individuales, con el fin de solucionar problemas comunes y lograr el mayor bienestar.

(B.5.GF5)

Las comunidades una vez organizadas y bien capacitadas, desarrollamos los Proyectos Comunitarios, avalados por la municipalidad y representantes de organismos gubernamentales que participaron unidos a nosotros en el diseño y puesta en funcionamiento.

(B.5.GF1)

Ahora nos toman más en cuenta, ahora si compartimos el reparto y la disminución del sufrimiento que acaparan la sociedad.

(B.5.GF8)

El camino recorrido ha contribuido a conceptualizar, establecer e integrar saberes populares y conocimientos técnicos, utilizando habilidades y capacidades de las propias comunidades que se cohesionaron alrededor de proyectos que ensalzan los derechos de los más pobres.

(B.5.GF3)

En este orden de ideas y proposiciones, el Estado aposto a la convergencia entre sus normas y funciones y la autonomía de las comunidades a través de la participación deliberativa en las discusiones públicas con el fin de posibilitar decisiones técnicas y políticas justas.
Los entes gubernamentales impulsamos y acompañamos en la diligencia de beneficios que formaron parte en la solución de la problemática existente en las comunidades, con el compromiso institucional de ayudar y colaborar a satisfacer las necesidades priorizadas, en tanto vayan encaminadas a poblaciones con mayor dificultad.

(B.5.GF3)

Se establecieron rutas claras y con participación de todos los departamentos de la alcaldía con el objetivo de dotar con herramientas indispensables para la ejecución y solución del problema priorizado, en concordancia con el plan de desarrollo local sustentable.

(B.5.GF2)

Se firmo un convenio en presencia del pueblo, donde la Gerencia de la Empresa, se compromete a cumplir lo solicitado por la municipalidad, avalada por el pueblo.

(B.5.GF2)

Para consolidar este proceso como proyecto político sostenible, los resultados permanecieron abiertos a las interpelaciones. En este sentido, se formalizaron diversos mecanismos organizados de seguimiento de las metas en distintos tipos de espacios colectivos, llevados a la práctica social de manera conjunta para informar a las comunidades en relación de los avances obtenidos.

Para lograr la sustentabilidad y continuidad del trabajo en equipo se dictaron talleres de control social que permitiera que las personas ejercieran todo lo relacionado con la acción de control social.

(B.6.GF7)

Se trabajó directamente con la gerencia de desarrollo comunitario para controlar todo el esfuerzo tanto de las comunidades como del gobierno municipal. Primeramente se capacitaba a las comunidades con talleres donde se les enseñaba como debía realizarse el control social.

(B.6.GF3)

Llevamos a cabo rendiciones de cuenta en reuniones periódicas de las comunidades con 
presencia de todos los habitantes y el Gobierno Municipal. El énfasis de este monitoreo se orientaba hacia la calidad de vida de los grupos de población más necesitados y con derechos más vulnerados como ancianos, niños y mujeres.

(B.6.GF4)

La entrega de cuentas de la gestión se realizo por la comunidad con la participación de los organismos gubernamentales involucrados en los proyectos comunitarios, donde se analizaban los avances y retrocesos sobre los resultados y entre todos sugerimos modificaciones sobre las forma de orientar nuevas actividades. (B.6.GF2)

La contraloría social produjo nuevas preguntas que, a su vez, modificaron los planteamientos y los modos posibles de interactuar sobre los problemas.

(B.6.GF5)

\subsection{Capacidad comunitaria}

En las iniciativas analizadas se trató de transformar las relaciones reales entre los humanos, de llevar los valores a la praxis, de fundar un mundo nuevo mediante la construcción de argumentos reflexivos, de eventos efectivos para la sociedad y el entorno, de una identidad narrativa propia, de ser responsable y recíproco al aceptar las consecuencias de la acción y de asumir el compromiso de acciones futuras. Estos procesos deliberativos fueron descritos por diversos actores.

Estas reuniones de trabajo se nutrieron por un conjunto de actitudes y conductas sociales del buen ciudadano entre nosotros, y se manifestaron en un grupo grande de asociaciones que inspiraban confianza solidaridad.

(C.7.GF1)

El argumento fundamental fue resaltar la importancia de la participación directa del ciudadano común en discusión sobre sus problemas y las alternativas de solución. De igual manera, hacer que los actores políticos entendieran este argumento y la influencia que podía tener la comunidad en los resultados electorales. (C.7.GF5)
Es importante señalar, que estábamos frente a una comunidad con inmensas cualidades para discutir, formular e implementar proyectos; tales como, responsabilidad, honestidad, nobleza, sentido de pertenencia, para lo cual se le dio mucha confianza.

(C.7.GF6)

La nobleza, responsabilidad, honestidad, confianza en sí mismo, de la comunidad; unida a la voluntad política de la Alcaldía y; con profunda mística, ética y el apoyo inmenso de muchos organismos nos incorporamos para reflexionar sobre nuestro problemas y asumir compromisos.

(C.7.GF3)

Con profunda satisfacción, debo resaltar la sinergia que se produjo, y la forma como se demostró que las personas cuando se les valora, se les toma en cuenta, participan y aportan ideas que garantizan a través de la democratización del conocimiento, el poder resolver problemas en menos tiempo y con pocos recursos. La reciprocidad fue clave principal para el éxito logrado.

(C.7.GF2)

Para explicitar su riqueza intersubjetiva, organizacional y política y concretar la construcción de elementos de intersubjetividad buscando consensos, tratados y compromisos de actuación colectiva; los participantes construyeron y se aglutinaron alrededor de redes socio-políticas. Por medio de estas, las impresiones y experiencias adquirieron significado más allá de los intereses individuales en la búsqueda de los objetivos comunes, así como nuevas habilidades y destrezas.

En el municipio existieron organizaciones comunitarias que trabajaban con distintos objetivos en los barrios: clubes, ligas de deporte, asociaciones, gremios que apoyaron en lo tocante a la salud y el bienestar; creándose comisiones para involucrar salud en todas las políticas.

(C.9.GF1)

Cada uno de los actores expone, decide, actúa y trabaja de acuerdo a sus ideas, respetando y aceptando las diferencias con el resto de los actores, logrando llegar a acuerdos que

Rev. Est. de Políticas Públicas, 5(1): diciembre 2018 - junio 2019 
les permitieran mediante la negociación sumar esfuerzos en pro de los proyectos.

(C.9.GF5)

A través de la gerencia de desarrollo comunitario se crearon las discusiones de desarrollo social, participación ciudadana y la red de posadas comunitarias. Los Comités de Salud se organizaron a las comunidades en gobierno comunitario, donde ellos ejercen el poder constitucional.

(C.9.GF2)

Los Consejos Comunales y los gobiernos de calle fueron las organizaciones creadas en las comunidades para garantizar el éxito en la gestión pública y el apoyo en la formulación e implantación de proyectos. El gobierno bajo recursos, donde los grupos comunitarios, desde una perspectiva colectiva buscaron acuerdos, convenios y desarrollan sus actividades para solución del problema.

(C.9.GF5)

Como resultados de los esfuerzos por establecer el orden e incrementar la predictibilidad de resultados sociales, se establecieron una serie de mecanismos de apoyo que coadyuvaron en la implementación de estas iniciativas. Entre estos se destacaron la intermediación de elementos ideológicos y procedimientos técnicos

La participación de la dirigencia política en las políticas de gestión permitió que las soluciones a los problemas fueran más rápidas y mejor organizadas.

(C.10.GF6)

La política de acción gubernamental se baso en la coordinación con todos los entes de gobierno para generar, contribuir y garantizar que el gasto sea racionalizado en función de calidad de vida de la población.

(C.10.GF2)

Se bajó a las comunidades la herramienta del presupuesto participativo a través ordenanzas con las cuales las comunidades tienen la oportunidad de planificar, ejecutar y controlar las obras comunitarias.

(C.10.GF3)
En este quehacer, tanto las comunidades como los equipos de los gobiernos locales y organismos gubernamentales, adquirieron nuevas habilidades o consolidaron su estilo de liderazgo. La función asumida por estos gobiernos comunitarios como mentores de procesos, en unión de actores públicos y privados, indica que las redes locales señalan el camino de la transformación del Estado. Las vivencias que describieron estos actores, fueron resumidas en tres estilos que convergen en todas las experiencias analizadas: liderazgo situacional, democrático y comunitario.

Para nosotros, el objetivo es el bien grupal. Para lograrlo, primeramente escuchamos y tomamos en cuenta todas las opiniones; luego estimulamos las habilidades de empatía y apoyo, las capacidades de colaboración, el sentimiento de pertenencia de grupo; para, finalmente actuar en consecuencia pero no para hacer lo mismo de antes sino para innovar, adaptándonos a cada modificación del entorno social y político a través de relaciones solidarias.

(C.8.GF1)

Lo esencial está en que los actores debemos tener el máximo de participación posible en la toma de decisiones, siendo una de nuestras tareas básicas facilitar la conciencia de la comunidad con relación a los recursos de poder que poseen y construir espacios para hacer viable su protagonismo, y es esta la razón por la cual buscamos instaurar un nuevo diálogo entre las instituciones, las personas y la comunidad a través de la conversación y la negociación permanente.

(C.8.GF5)

El líder se esfuerza en reconocer y potenciar a los miembros de la organización y se orienta a transformar las creencias, actitudes y sentimientos de sus seguidores, pues no solamente gestiona las estructuras sino que influye en la cultura para cambiarla.

(C.8.GF6)

Nuestras capacidades individuales las colocamos al servicio de la comunidad y el bien colectivo con equidad y justicia social. En lo particular, me ocupo de orientar la organización del gobierno local, motivo para que aumente la participación del equipo, estimulo en el grupo nuestras capacidades colectivas como recurso

Rev. Est. de Políticas Públicas, 5(1): diciembre 2018 - junio 2019 
de poder y fortalecimiento de la identidad colectiva.

(C.8.GF2)

Los argumentos socio-políticos que prevalecieron en estas iniciativas, se relacionaron con el fortalecimiento de la democracia como sistema. En este sentido, destacamos el concepto de justicia social, percibido como el reconocimiento y el respeto a las normas de convivencia de las personas que comparten derechos, privilegiando el bien común para los más necesitados, con las mismas oportunidades de diálogo para toda la sociedad. Asimismo, estos procesos participativos destacaron los ejemplos de pluralismo y tolerancia como actitud de reconocimiento de la diversidad y el respeto que tienen los demás a pensar y opinar de manera diferente.

El bienestar de la población era el objetivo estratégico de la Alcaldía, y para ello era fundamental tener voluntad política y liderazgo, y esto, unido a la organización y capacidad de dirimir argumentos por parte de la comunidad, se conjugaron.

(C.11.GF2)

Lo hacemos de modo participativo, escuchando, aceptando críticas y respondiéndolas, observando las necesidades del grupo, y no sus intereses personales. Somos canalizadores de inquietudes, respetando las diferencias del conjunto pero, dando un mayor peso a las comunidades con los derechos más vulnerados.

(C.11.GF5)

Somos solidarios, nos apoyamos en el sentido de justicia y tolerancia del colectivo para llevar adelante los planes que se discuten entre todos, respetando las normas de convivencia que nos proponen los grupos de debate y las leyes jurídicas y sociales.

(C.11.GF1)

\subsection{Competencias comunitarias}

Los actores participantes en las diversas iniciativas comprendieron que era fundamental para los objetivos que perseguían, ubicarse en el lugar de las otras personas y responder adecuadamente a sus estados emocionales a través de aceptar a los otros tal como son: enfocar los problemas y las relaciones desde el punto de vista de la realidad común; actuar sin esperar el elogio y agradecimiento de los demás; crear consenso y grupos de apoyo, relacionados con la gestión de conflictos, la negociación y la mediación; y generar confianza para conseguir modificar el comportamiento de las personas.

El diálogo abierto con todos los participantes nos permitió entender que el principal sentimiento es el de la unidad donde todos entendimos que juntos y comprometidos las cosas se pueden conseguir.

(D.12.GF4)

El contacto permanente con la realidad nos hizo sentir que ser una comunidad integrada, significa ser heterogénea, sin embargo, ser homogénea desde el punto de vista de las necesidades. Eso fue precisamente lo que influyó en la participación comunitaria.

(D.12.GF8)

La empatía con todos los que vivían en las comunidades y que estaban interesados en solucionar los problemas y así gozar de mejor calidad de vida, me motivó a asistir permanentemente a las deliberaciones para comprometerme y participar en la formación de redes y vocerías sin esperar que me lo agradecieran, solo que todos nos uniéramos para lograr solucionar nuestras necesidades.

(D.12.GF5)

El grado de compromiso de los grupos, la unión, la voluntad, el querer hacer las cosas bien, facilito poder dirimir nuestras diferencias y así llegar a acuerdos y responsabilizarnos en la planificación y ejecución de los proyectos, esto logró mejorar la calidad de los resultados. (D.12.GF1)

La democratización de la participación en la solución de los problemas, el creer en el gobierno municipal que daba respuestas oportunas, nos dio suficiente confianza para creer que si podía cambiar la conciencia de la gente y los modos de vida que teníamos de antes.

(D.12.GF4)

Estos sentimientos de integración y de pertenencia a una comunidad reflejaron la percepción de apoyo para promover la salud y el bienestar. La comunidad 
actuó como un elemento de conexión entre la persona y las redes, conformando un engranaje a través del cual se canalizó el apoyo social; y, en este sentido, los contactos con la comunidad, la pertenencia activa a grupos Comités de Salud y Consejos Comunales, así como el uso de las asociaciones comunitarias constituyeron escenarios donde se movilizaron y se logró el apoyo social.

Las redes que se crearon con ansias de que sus pobladores mejoraran la calidad de vida y adquirieran el bienestar tan necesario, fueron la clave para que todos los ciudadanos se conectaran entre sí para unificar las ideas y las ayudas.

(D.13.GF1)

El sentido de pertenencia, las metas y logros satisfactorios obtenidos en colectivo, despertó sentimientos con apoyo social, apoyo educativo, apoyo deportivo, apoyo en salud, con toda la familia.

(D.13.GF4)

El proceso de integración inter-parroquial, comunitaria, familiar, gubernamental, para el logro de éxitos de los fines esperados, nos ayudo en la articular de acciones donde la comunidad formaba parte de la solución de los problemas, para rendir los presupuestos y las soluciones fueran de mejor calidad.

(D.13.GF1)

En algunos casos, grupos sectarios se constituyeron en intermediadores que buscaban desarrollar clientelismo, pero las organizaciones comunitarias con autoestima y amor con justicia, se movilizaron rápidamente y toda la comunidad les retiro en apoyo.

(D.13.GF8)

Hacer un solo bloque comunitario ganó fuerza para el logro y aprovechamiento de los recursos, tanto de la comunidad como del gobierno, para alcanzar los objetivos que nos propusimos con la buena pro de toda la población.

(D.13.GF5)

Esta responsabilidad ética generada por las ideas de reconocimiento, de solidaridad y de mutuo equilibrio entre amor y justicia, proporcionaron los elementos desencadenantes para la conformación del contrato social, que nace de un consentimiento virtual que aflora en la reflexión. Se trató de un lazo político para crear a idealidad de la equidad de cada uno frente a todos. Esta idealidad configuró la verdad de la política pública y la realidad del Estado, es decir, el advenimiento de una legitimidad producto del equilibrio entre la solidaridad, la justicia social y los derechos de las comunidades.

En este proceso, la Comunidad se organizó con el Estado, y esta organización es la articulación de diversas instituciones concretas. Esta articulación y organización permitieron acciones humanas cargadas de conductas direccionadas, proyectadas, constructivas.

El trabajo casa por casa, previo a las asambleas, refrendó la integración grupal con relación a las vivencias o experiencias de nuestro Municipio. Luego, en las reuniones de trabajo logramos obtener información consensuada, oportuna, pertinente, efectiva, con impacto social que se expuso al gobierno municipal y los organismos presentes para de seguido, conformar y distribuir los acuerdos por escrito para hacer del conocimiento colectivo.

(D.14.GF1)

Nos comunicamos permanente y de manera coherente con las instituciones ya sean nacionales, regionales, municipales con el fin de mejorar las necesidades encontradas en el diagnostico participativo y alcanzar acuerdos y recursos en cuanto a los aspectos importantes. (D.14.GF5)

Los canales utilizados para tal fin fueron la gerencia de desarrollo Comunitario-Alcaldía, asistencia a sesiones del Concejo Municipal, canales regulares de los Ministerios para descubrir y solucionar problemática existente.

(D.14.GF4)

Fue un punto de encuentro entre salubristas, urbanistas, ambientalistas, y comunidades cuyo acercamiento a través de la acción, permitió un sinergismo favorable para la comunidad a través de la coordinación nacional, regional y local, con Comités de Salud. De allí surgió un pacto firmado.

(D.14.GF1)

Rev. Est. de Políticas Públicas, 5(1): diciembre 2018 - junio 2019 
Se entregaron recursos contra proyectos comunitarios sin mirar colores políticos, ni credo, ni raza todo bajo el principio del trabajo ganarganar con justicia social.

(D.14.GF2)

\subsection{Impacto en salud}

La expectativa de años aumento en los municipios en los cuales se obtuvo información: la evolución fluctuó entre 0,6 hasta 4,5 años de vida. Con relación al indicador que mide la supervivencia de la población de un año de edad, esta tasa disminuyo en estos municipios en proporciones que van desde un $4 \%$ hasta $44 \%$ (Tabla 3). En este sentido, los municipios con mayores necesidades básicas satisfechas, realizaron impresionantes progresos y ello se evidencio en el hecho de que las interacciones que se llevaron a cabo en poblaciones que poseen mayor capital social, proporcionan mayores posibilidades de interactuar sobre factores evitables e injustos que condicionan diferencias en oportunidad de vida (Málaga y Castro Ramírez, 2001); a través de la labor pro-activa y estratégica de líderes comunitarios, dirigentes, y comunidades directamente vinculados con la política pública saludable, con el fin de impulsar y fortalecer la participación ciudadana y la intersectorialidad como elementos esenciales de justicia social y; la presencia de responsabilidad social y de voluntad política por parte de las autoridades.
Sin embargo, autores como Muntaner y Lynch (1999), aclaran que actuar sólo sobre el capital social planteados en valores y principios de solidaridad y responsabilidad compartida, tendería erróneamente a atribuirle responsabilidad por la buena o mala salud de acuerdo a las condiciones de la población. Esto último pudiese explicar el fenómeno sucedido con la mortalidad materna, que por el contrario se incrementó significativamente a lo largo de los años analizados, debido presumiblemente a restricciones en los procesos de desarrollo de la capacidad productiva que operan en el contexto del sistema de salud y que no fueron objeto de la presente investigación. Con todo, debemos acotar que en comunidades con población escasa, como sobre las cuales se desarrolló el estudio, puede sobrestimar la diferencia de la mortalidad con respecto a su impacto real, ya que un pequeño número de defunciones maternas ocasionan una elevación importante de la tasa (Blanco Muñoz et al., 1994). 
Tabla 3: Indicadores de salud en municipios Zamora, Andrés Eloy Blanco y Moran, por quinquenios. 1994-2013

\section{Indicadores}

Zamora

A. E. Blanco

Moran

\begin{tabular}{lcccccccccccc} 
& $\mathrm{a}$ & $\mathrm{b}$ & $\mathrm{c}$ & $\mathrm{d}$ & $\mathrm{a}$ & $\mathrm{b}$ & $\mathrm{c}$ & $\mathrm{d}$ & $\mathrm{a}$ & $\mathrm{b}$ & $\mathrm{c}$ & $\mathrm{d}$ \\
\hline NBI \% & 23,8 & 8,4 & $\ldots$ & 6,1 & 83,6 & 21,9 & $\ldots$ & 17,4 & 57,0 & 16,3 & $\ldots$ & 7,0 \\
Exp. Vida al nacer & 71,8 & 73,5 & 72,5 & 72,5 & $\ldots$ & 72,5 & 77,3 & 77,0 & $\ldots$ & 76,3 & 77,5 & 76,9 \\
TMI x 1000 & 15,0 & 13,0 & 17,4 & 14,4 & 35,7 & 33,1 & 20,0 & 20,7 & 29,3 & 26,1 & 17,5 & 16,4 \\
TMM x 100.000 & 0 & 0 & 58,5 & 34,1 & 20,0 & 36,1 & 18,6 & 84,4 & 39,6 & 62,7 & 46,3 & 77,3 \\
\hline a 1994-1998 & & & & & & & & & & & &
\end{tabular}

b 1999-2003

c 2004-2008

d 2009-2013

Fuente: Elaboración propia en base a registros oficiales.

\section{Discusión}

Los principales hallazgos de la investigación se agruparon en las cuatro categorías anteriormente señaladas, que caracterizan al capital social como determinante social de la salud y sustenta la formulación e implementación de politicas publicas saludables en el país.

En este orden, el sentido de comunidad reconoce las experiencias que los participantes tuvieron en relación con el sentimiento de membresía de quienes conforman una comunidad y la percepción de confianza compartida de que las necesidades de los actores encuentran respuestas a través del compromiso de estar juntos. La eficacia colectiva en estos procesos se manifiesta en la capacidad deliberativa de los grupos poblacionales para alcanzar una meta específica; se relacionó con el acceso garantizado a la ciudadanía y a los derechos económicos, políticos y sociales; así como con las posibilidades de participación efectiva, conexión y solidez de las redes de reciprocidad social en la esfera política. Asimismo, la capacidad comunitaria responde a cómo los participantes reconocieron las características que afectaron su habilidad para identificar, movilizar y responder a los problemas. Involucró un modo de actuar que requirió del cabildeo, la planeación de políticas, la negociación e implementación de una manera que pudo ser interpretada como muy política o de alguna otra competencia; elevar la conciencia política a través de la apropiación de sus propios valores y autonomía. Por último, la competencia comunitaria traduce los componentes de la comunidad que le permitieron colaborar efectivamente en la identificación de sus problemas y necesidades, alcanzar un consenso trabajado respecto a sus objetivos y prioridades, acordar vías y medios para implementar dichos propósitos y colaborar efectivamente en las acciones concertadas.

El tema de políticas públicas saludables en Venezuela se define partiendo de dos vías democráticas; por un lado, un enfoque de liberalismo social reflejado en el desarrollo de libertades y capacidades para la generación de una vida digna en los ámbitos locales mediante el fortalecimiento de las alianzas sociedad civil-gobiernos y el empoderamiento de individuos y comunidades para la generación de gobernanza; y otro, fundamentado en la organización y estructuración de espacios vitales para los ciudadanos, favorecido por la movilización de recursos para el ejercicio del poder popular. Ambas propuestas tienen como referentes el Proyecto Municipios hacia la Salud y las Misiones Sociales, las cuales las caracterizan como instrumentos guía para la inclusión social en pro del desarrollo humano y la igualdad de oportunidades con el fin de alcanzar el bienestar colectivo.

En los municipios donde se iniciaron estos procesos, las políticas públicas saludables incidieron sobre desiguales condiciones, oportunidades y recursos resultantes de diferentes dinámicas vulnerables arraigadas en la vida cotidiana de las personas (Programa de las Naciones Unidas para el Desarrollo, 2014). Asimismo, procuraron la potenciación las capacidades humanas para actuar sobre aquellos determinantes claves que impactan sobre la salud de la población y posibilitan el goce y bienestar de vida digna y democrática de los ciudadanos (Organización Panamericana de la Salud, 2006).

Se reconoce que lo más relevante en estas experiencias, lo constituyen su corresponsabilidad en la construcción de ciudadanía cimentada en la universalidad de los derechos individuales, políticos y civiles; el reconocimiento de la interdependencia de 
la comunidad y el Estado para incidir sobre aquellos determinantes claves que fortalecen estos derechos en los ámbitos locales; y el compromiso éticopolítico sobre las obligaciones que de ellos se derivan en el ejercicio de una verdadera democracia. Los elementos que explicaron estas aptitudes fueron: la construcción colectiva local como espacio de convergencia de la identidad y subjetividades de los ciudadanos; la conformación de una nueva manera de interpretar la institucionalidad con capacidad de incidir sobre el sistema político con igualdad de oportunidades al acceso de una mejor calidad de vida sustentada en la promoción de la salud; la búsqueda de la justicia y equidad como objetivo vinculante de la ética del deseo, la moral del deber, y la sabiduría práctica.

Estos planteamientos, se nutren en la construcción de capital social que amplía las oportunidades para las innovaciones a través de coproducción del conocimiento de la sociedad; además, crea nuevos mecanismos de coordinación con los organismos gubernamentales, alcaldes y demás actores del gobierno local. Entre las condiciones, particularmente destacadas a las políticas públicas saludables, encontramos: el sentido de pertenencia de la comunidad; el sentido de competencia compartida para alcanzar metas concretas; las habilidades para identificar, movilizar y responder a los problemas comunes; y el compromiso con la comunidad, el apoyo social de la comunidad y mecanismos de articulación política para facilitar la interacción participante y la toma de decisiones.

El conocimiento para construir valores compartidos, surge de la confluencia de esfuerzos, saberes y vivencias para impulsar normas y conductas saludables; de este modo desarrollan una integración grupal caracterizada por un equilibrio entre la solidaridad; la responsabilidad compartida; la justicia social basada en similares oportunidades para el desarrollo de los más necesitados; y los derechos individuales, políticos y civiles de las comunidades (Lévy y Malo, 2010).

El carácter de la forma organizativa en redes se adapta en función de las necesidades colectivas determinadas por los factores que afectan a la salud y producen inequidades que afectan sus derechos. Se establecen entonces dinámicas que permiten adquirir nuevas competencias políticas y generan un conjunto de prácticas desarrolladas por los actores societales, que permiten un nuevo significado de la relación salud-bienestar (García-Ramírez y Vélezálvarez, 2013).
Las modalidades de interacción se concentran en la reflexión de lo que implica ser y actuar como ciudadano al momento de establecer relaciones con el gobierno y con sus instituciones. A partir de esto, se observan actores con capacidad de participar de manera activa en redes sociales empoderadas, capaces de generar consenso a través de sentimientos de confianza compartida con las instituciones y gobiernos locales a fin de integrar recursos, visiones, valores, marcos ideológicos o pragmáticos; acercar las alternativas de solución que originaron las necesidades fundamentales de las comunidades, así como las desfases entre sectores, entre sociedad y sectores, y entre gobierno-Estado y sociedad; y establecieron mecanismos de rendición de cuentas (Restrepo, 2002).

La participación es deliberativa puesto que genera suficiente debate político sobre los problemas mediante mayor dominio explicativo sobre la realidad y claridad en la calificación de los problemas; de igual manera, promueve valores y conceptos, da formas a objetivos y líneas de acción de manera colectiva, construye vínculos comunicativos para movilizar energías y voluntades, y formula soluciones viables y factibles. Una vez que los actores asumen sus nuevas competencias ciudadanas, la comunidad es capaz de interactuar sobre los determinantes sociales de la salud, construyendo agendas participativas cuyos objetivos fundamentales fueron la satisfacción de sus derechos y la inclusión social, bajo el precepto ético de buscar la equidad con justicia social asociado a un proceso acelerado de integración y cohesión social, mediante esfuerzos conjuntos que permiten aproximar los derechos y oportunidades hacia beneficios colectivos.

\section{Conclusiones}

Se entiende por políticas públicas saludables la secuencia de respuestas integradas y sostenidas en todas las políticas del Estado, producto de procesos multisectoriales y transdisciplinarios de mediación social; con el fin de garantizar que todos los miembros de la sociedad tengan una posibilidad real e igual de participar en las decisiones del Estado a través de una transformación significativa en las formas de interacción entre actores políticos, grupos o redes comunitarias e instituciones; dentro de un entorno histórico-cultural común, en cuyas dinámicas e interrelación se describen los cambios sobre una mejor calidad de vida y salud de la población.

Las modalidades de interacción de las relaciones Estado-Sociedad practicadas en estas iniciati-

Rev. Est. de Políticas Públicas, 5(1): diciembre 2018 - junio 2019 
vas, han planteado un desafío teórico alrededor a la toma de decisiones públicas, los sistemas políticos derivados de las relaciones gobierno-ciudadano y las nuevas actitudes y aptitudes apoderadas por este último. Se concentraron, primordialmente, en la reflexión de lo que implica ser y actuar como ciudadano al momento de establecer relaciones con el gobierno y con sus instituciones. A partir de esto, proponen un nuevo significado del poder político con que cuenta la ciudadanía para participar, configurar y decidir en la vida política del Estado, derivado de asumir el papel y las responsabilidades que ello encarna.

En estas iniciativas, la participación fue deliberativa, puesto que genera suficiente debate político sobre los problemas, mediante mayor dominio explicativo sobre la realidad y claridad en la calificación de los problemas; de igual manera, promueve valores y conceptos, da formas a objetivos y líneas de acción de manera colectiva, construye vínculos comunicativos para movilizar energías y voluntades, y formula soluciones viables y factibles.

En estos procesos, el carácter de la forma organizativa en redes, se moldeó en función de las necesidades colectivas determinadas por los factores que afectan a la salud y producen inequidades que afectan sus derechos. Se establecieron entonces dinámicas que permitieron adquirir nuevas competencias políticas y generan un conjunto de prácticas desarrolladas por los actores societales, que asentaron un nuevo significado de la gobernanza para la salud y el bienestar, derivado de asumir el papel protagónico y las responsabilidades que ello implica.

Una vez que los actores asumieron sus nuevas competencias ciudadanas, como derecho de membresía y pertenencia a una comunidad, expresada en la posibilidad de alcanzar el bien compartido y hacer efectiva una mejor calidad de vida, la comunidad fue capaz de interactuar sobre los determinantes sociales de la salud, construyendo agendas participativas, cuyos objetivos políticos fundamentales fueron la satisfacción de los derechos sociales y la inclusión social, bajo el precepto ético de buscar la equidad con justicia social.

El desarrollo eficaz de estas agendas estuvo asociado a un proceso acelerado de integración y cohesión social, mediante esfuerzos conjuntos que permitieron aproximar los derechos y oportunidades hacia beneficios colectivos. Asimismo, la capacidad y estilo de liderazgo que asumieron los actores en las redes comunitarias, constituyó un factor clave como fuente de legitimidad y un recurso para la negociación polí- tica que les proporcionó las herramientas necesarias para desarrollar sus actividades.

Como horizonte de mediano plazo, consideramos que al menos en estas iniciativas se asoma una democracia social, resultados de una ampliación de oportunidades sociales y de movilidad social ascendentes, habilitados igualitariamente en toda la estructura social; mediante procesos como la apropiación, el empoderamiento y la participación; y que concluyen en procesos autonómicos muy propios de cada comunidad (Figura 2).

\section{Referencias}

Blanco Muñoz, J., Hernández Muñoz, R., Montiel Cervantes, A., Huerta Pérez, L., Medina Corona, S., Ojeda Velázquez, M., Cruz Valdez, A., Dubón Tomé, F., Rodríguez Martínez, M., y Recio Pérez, J. (1994). Mortalidad materna en el área huichol del estado de jalisco, méxico. $S a$ lud Pública Mex, 36(3):263-268.

Botelho Josgrilberg, F. (2008). La fenomenología de maurice merleau-ponty y la investigación en comunicación. Signo y Pensamiento, 27(52):6883.

Canto Chac, M. (2008). Gobernanza y participación ciudadana en las políticas públicas frente al reto del desarrollo. Polít. Cult, 30:9-37.

Commission on Social Determinants of Health (2008). Closing the gap in a generation: health equity through action on the social determinants of health, Final Report. WHO, Geneva.

Dantas Guedes, D. y Moreira, V. (2009). El método fenomenológico crítico de investigación con base en el pensamiento de merleau-ponty. Ter Psicol, 27(2):247-257.

De Salazar, L. y Díaz Grajales, C. (2004). La evaluación-sistematización: una propuesta metodológica para la evaluación en promoción de la salud. un estudio de caso en cali, colombia. Ciênc. saúde coletiva, 9(3):545-555.

Declaración de Adelaida sobre la Salud en Todas las Políticas (2010). Hacia una gobernanza compartida en pro de la salud y el bienestar. OMS/Gobierno de Australia Meridional, Adelaide.

D'Elia y De Negri, A. (2006). La estrategia de promoción de la calidad de vida". 
Figura 2: Aporte de las políticas públicas saludables

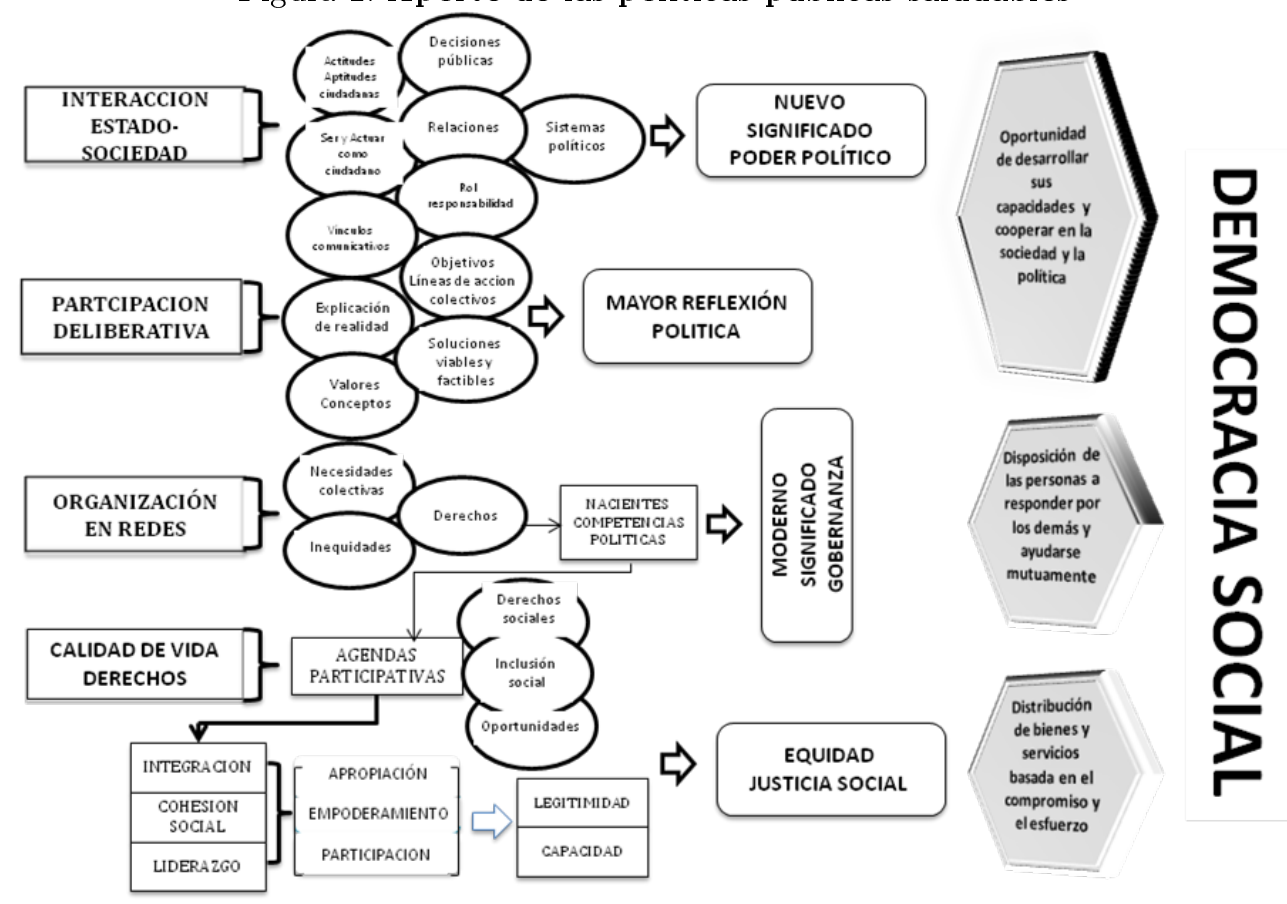

Figura 3. Aportes de las politicas publicas saludables. Elabor ación propia

Fuente: Elaboración propia.

García-Ramírez, J. y Vélez-álvarez, C. (2013). América latina frente a los determinantes sociales de la salud: Políticas públicas implementadas. Rev. salud pública, 15(5):731-742.

Glasser, B. y Strauss, A. (1967). The discovery of Grounded Theory: Strategies for Qualitative Research. Aldine Publishing Company, Chicago.

Gurdián-Fernández, A. (2007). El Paradigma Cualitativo en la Investigación Socio-Educativa. CECC/ AECI, San José.

Lacruz, T. (2006). Balance sociopolítico: Una ciudadanía social inacabada". En Maingon, T., editor, Balance y perspectivas de la política social en Venezuela. Ildis, Caracas.

Lefevre, F. y A.M, L. (2014). Discourse of the collective subject: social representations and communication interventions. Texto \& Contexto Enfermagem, 23(2):502-507.

Lévy, J. y Malo, M. (2010). De la participación en salud a la construcción del poder popular: Experiencias para el debate. IAES, Caracas.

Lochner, K., Kawachi, I., y Kennedy, B. (1999). Social capital: a guide to its measurement. Health \& Place, 5(4):259-270.
Málaga, H. (1996). Los municipios hacia la salud: La experiencia venezolana”. En H. Málaga, L. Manzanilla, M. T., editor, Proyecto Municipios hacia la Salud. Experiencia Venezolana. MSAS/OPS/RVMHS, Caracas.

Málaga, H. (1998). Municipio saludable: una estrategia de justicia social. MedUNAB, 1(3):200203.

Málaga, H. y Castro Ramírez, M. (2001). Como empoderar a los excluidos en el nivel local. En H. Restrepo, H. M., editor, Promoción de la salud: Como construir vida saludable. 1 a reimpresión. Editorial Médica Panamericana, Bogotá.

Mandl, J. (2018). Nuevas Prácticas y Significados en Politicas Públicas Saludables. Un Modelo de Gestión. Beau Bassin.

Martínez Miguélez, M. (2004). Los grupos focales de discusión como método de investigación. Heterotopia, 10(26):59-72.

Martínez-Salgado, C. (2012). El muestreo en investigación cualitativa: principios básicos y algunas controversias. Ciência \& Saúde Coletiva, 17(3):613-619. 
Mayz Díaz, C. (2009). ¿cómo desarrollar, de una manera comprensiva, el análisis cualitativo de los datos? Educere, 13(44):55-66.

Muntaner, C. y Lynch, J. (1999). Income inequality, social cohesion, and class relations: a critique of wilkinson's neo-durkheimian research program. Int J Health Serv, 29(1):59-81.

Organización Panamericana de la Salud (2006). Guía técnica operativa para la elaboración, implementación y evaluación de Políticas Públicas Saludables. OPS, Bogotá.

Programa de las Naciones Unidas para el Desarrollo (2014). Informe sobre desarrollo humano 2014. Sostener el Progreso Humano: Reducir vulnerabilidades y construir resiliencia. PNUD, New York.

Restrepo, H. (2002). Experiencia del municipio de versalles, departamento del valle: una mirada desde la promoción de la salud. Rev. Fac. Nac. Salud Pública, 20(1):135-144.

Roth Deubel, A. (2008). Perspectivas teóricas para el análisis de las políticas públicas: ¿de la razón científica al arte retórico? Estudios Políticos, 33.

Ruedas Marrero, M., Ríos Cabrera, M., y Nieves Sequera, F. (2009). Epistemología de la investigación cualitativa. Ucere, 13(46):627-635.

Salamanca, A. y Martín-Crespo, C. (2007). El muestreo en la investigación cualitativa. Nure investigación, 27.

Sandín Esteban, M. (2000). Criterios de validez en la investigación cualitativa: de la objetividad a la solidaridad. Revista de Investigación Educativa, 18(1):223-242.

Sapag, J. y Kawachi, I. (2007). Capital social y promoción de la salud en américa latina. Rev. Saúde Pública, 41(1):139-49.

Segunda Conferencia Internacional sobre Promoción de la Salud: Políticas públicas saludables (2008). OMS, Adelaide, South Australia.

Strauss, A. y Corbin, J. (1998). Basics of qualitative research: Techniques and procedures for developing Grounded Theory. SAGE publications, London.
Toba Darriba, M. (1996). Desarrollo de las experiencias de municipios hacia la salud en venezuela". En H. Málaga, L. Manzanilla, M. T., editor, Proyecto Municipios hacia la Salud. Experiencia Venezolana. MSAS/OPS/RVMHS, Caracas.

Universidad Central de Venezuela y Ministerio de Salud y Asistencia Social (1993). Perfiles de mortalidad según condiciones de vida: Experiencia en venezuela. Boletín Epidemiológico, 14(3):11-14.

Vasilachis de Gialdino, I. (2009). Ontologische und epistemologische grundlagen qualitative forschung. Forum Qualitative Social Research, $10(2)$. 